\title{
STUDI ENCLAVE WILAYAH PERBATASAN RI - PNG BERDASARKAN ZONA TAMAN NASIONAL WASUR (STUDI KASUS WILAYAH SOTA, KABUPATEN MERAUKE, PAPUA)
}

\author{
Oleh: \\ Agustan Latif 1), Agustan 2) \\ ${ }^{1}$ Fakultas Teknik, Universitas Musamus Merauke. email: agustan@unmus.ac.id \\ ${ }^{2}$ Fakultas Teknik, Universitas Musamus Merauke. email: mulianagustan2011@gmail.com
}

\begin{abstract}
ABSTRAK
Penelitian ini merupakan kajian pada zona Taman Nasional Wasur (TN Wasur), dalam pemanfaatan enclave yang kemudian menjadi kawasan perbatasan Negara Kesatuan Republik Indonesia (NKRI) dengan Papua Nugini di Distrik Sota, Kabupaten Merauke. Secara khusus wilayah perbatasan Sota dan PNG merupakan wilayah konservasi TN Wasur, proses pengelolaannya berdasarkan zonasi yang telah ditetapkan oleh Direktorat Jenderal Perlindungan Hutan dan Konservasi Alama (PHKA). Metode penelitian yang dilakukan yakni melalui kajian pustaka, wawancara dan survei lapangan. Berdasarkan hasil kajian dari penelitian ini merekomendasikan bahwa pengelolaan zona enclave yang dikelurkan oleh Dirjen PHKA balai Taman Nasional Wasur seluas 3000 ha dari kawasan konservasi kehutanan untuk warga baru sebanyak $500 \mathrm{KK}$ yang merupakan warga transmigrasi. Permanfaatan zona enclave sangat berhasil dengan adanya interaksi sosial maupun ekonomi susu-suku asli Papua yang ada di Sota Kabupaten Merauke yang merupakan wilayah NKRI dengan negara tetangga PNG, dengan interaksi tersebut memunculkan adanya jalur-jalur setapak sebagai akses darat antara kedua negara yang kemudian akses darat tersebut dipisahkan dengan garis batas negara. Pemanfaatan zona enclave memunculkan pertumbuhan penduduk dan perekonomian masyarakat perbatasan Sota yang sangat signifikan.
\end{abstract}

\section{Keywords: Zona enclave, Balai Taman Nasional Wasur, RI, PNG}

\section{PENDAHULUAN}

Kajian penelitian ini merupakan studi pemanfaatan wilayah enclave Taman Nasional Wasur (TN Wasur) yang kemudian berkembang menjadi wilayah perbatasan Negara Kesatuan Republik Indonesia (NKRI) dan Papua, sehingga dipandang penting dalam menciptakan pemanfaatan lahan yang sesuai dengan keperuntukan lahan tersebut guna meningkatkan pertumbuhan penduduk, pembangunan, kesejahteraan masyarakat serta menjaga stabilitas keamanan di wilayah perbatasan NKRI. Wrenfridus Taena (2009) dalam kajiannya menyatakan bahwa willayah perbatasan negara menrupakan kajian yang unik karena aktivitasnya dipengaruhi oleh wilayah lainnya yang berbatasan. Wilayah perbatasan merupakan kesatuan secara geografis beserta sumber daya yang terkandung di dalamnya perlu dikembangkan berdasarkan prioritas pembangunan dengan cara mengoptimalakan pemanfaatan pemberdayaan sumber daya yang tersedia baik sumber daya manusia, sumberdaya buatan, maupun sumber daya sosial serta peningkatan produktivitas secara ekonomi.

Wilayah perbatasan menjadi strategis dengan diadakan pengembangan pusat-pusat pertumbuhan ekonomi baru dapat dilakukan untuk meningkatkan kinerja ekonomi wilayah perbatasan Kabupaten 
Timor Tengah Utara dengan Distrik enclave Oekusi. Dengan pembentukan pusat-pusat pertumbuhan baru diharapkan dapat melayani daerah hinterland dengan mendistribusikan kebutuhan masyarakat di wilayah hinterland baik kebutuhan produksi maupun konsumsi. Hal ini akan memberikan nilai tambah yang tinggi bagi masyarakat serta mengurangi biaya transportasi (Wirefridus Taena dkk., 2010).

Wilayah Taman Nasional Wasur dan Suaka Margasatwa Tonda (Tonda Wildlife Management Area) yang berada di Papua Nugini, kedua kawasan tersebut didiami oleh masyarakat adat yang memiliki adat istiadat yang sama secara turun temurun, sebelum kedua kawasan tersebut ditetapkan sebagai kawasan konservasi. Hubungan kekerabatan yang sangat erat serta memiliki hak ulayat yang tidak bisa dipisahkan oleh batas kedua negara menjadikan kawasan tersebut menjandi pusat aktivitas kehidupan bermasyarakat di wilayah perbatasan (RI - PNG). Suku Kanume dan Yei yang berda di wilayah Sota, Kondo, Erambu, Torai, Kwel dan Bupul memiliki hak-hak tradisional di Negara Tetangga PNG begitu pula sebaliknya. Kedekatan hubungan msyarakat adat antara kedua negara selama ini masih terjalin dengan baik, hal ini ditunjukkan dengan kegiatan-kegiatan seperti perayaan hari kemerdekaan negara, masyarakat adat kedua negara saling mengunjungi dan mengikuti kegiatan yang diselenggarakan di wilayah Sota dan Weam PNG.

Keterwakilan wilayah adat dalam kawasan TN Wasur diharapkan dapat menjadi dasar penataan zonasi TN Wasur, sehingga memberikan peran dan tanggung jawab bersama dengan masyarakat adat dalam pengelolaan taman nasional. Demikian halnya dengan pengalokasian ruang kelola bersama dengan stakeholder, hal ini dimaksudkan agar terdapat kejelasana alokasi ruang serta peran dan tanggung jawab stakeholder dalam melaksanakan program pembangunan daerah yang terkait dengan keberadaan Taman Nasional Wasur, khususnya pemanfaatan zona enclave (Balai Taman Nasional Wasur, 2011).

Wilayah hutan Provinsi Papua merupakan hutan terluas yang ada di Indonesia dan Kabupaten Merauke merupakan bagian di dalamnya dengan luas hutan mencapai 95,3\% dari total luas wilayah, warisan alam yang luas tersebut menjadi sumber daya yang harus dijaga, tetapi banyak faktor yang menjadi permasalahan dalam menjaga kelestarian hutan ini. Menurut data pemerintah, rata-rata deforestasi di Papua mencapai 143.680 hektar per tahun. Berdasarkan keperihatinan kerusakan hutan, maka dikhawatirkan hal ini akan mengekibatkan perubahan pada kondisi ekosistem Taman Nasional Wasur.

Reny Sawitri dan Yalin Adelina (2016) dalam kajiannya memaparkan bahwa dalam pengelolaan suatu zona yang penataan ruangnya tidak sesuai dengan aspek biofisik dapat menimbulkan dampak negatif kepada zona lainnya termasuk masyarakat setempat. Sebagai contoh adanya pengembangan fasilitas umum seperti sarana dan prasarana di wilayah zona khusus, di satu sisi merupakan bentuk kemudahan aksesibilitas, di sisi lain dapat menjadi ancaman bagi taman nasional bila disalah gunakan. Mempertimbangkan hal tersebut, maka penelitian ini mengkaji zona pemanfaat khusus dari TN Wasur, menghubungkan antara zona pamanfaatan dengan mempertimbangkan topologi etnis lokal Papua dan masyarakat yang mendiami zona tersebut serta melihat pertumbuhan dari pemanfaatan enclave TN Wasur.

Berdasarkan Peraturan Pemerintah Nomor 28 Tahun 2011 diamanatkan bahwa untuk mewujudkan fungsi taman nasional, maka kawasan taman nasional itu harus dikelola dengan sistem zonasi. Zonasi taman nasional pada dasarnya merupakan pengaturan ruang dalam taman nasional 
dengan mempertimbangkan kajian-kajian dari aspek ekologis, sosial, ekonomi dan budaya masyarakat lokal. Selanjutnya sesuai dengan Peraturan Menteri Kehutanan Nomor P.56/MenhutII/2006 pasal 3 disebutkan bahwa zona hutan terdiri dari zona inti, zona rimba, zona pemanfaatan, dan zona lain. Zona lain seperti zona tradisional, zona rehabilitasi, zona religi, budaya dan sejarah, serta zona khusus. Pembagian zona-zona dimaksud tentunya disesuaikan dengan kondisi potensi sumber daya alam di setiap taman nasional.

\section{METODE PENELITIAN}

Metode penelitian dalam kajian ini bersifat deskriptif dengan menggunakan pendekatan kualitatif. penelitian kualitatif menjadi pilihan yang tepat untuk melihat fenomena will to improver dalam pengelolaan batas wilayah negara di perbatasan. Tahapan yang dilakukan yakni Pengumpulan, Analisa Data, dan Konsultasi Publi. Untuk mendukung hal tersebut diperlukan data primer dan sekunder. Data primer diperleh dengan cara observasi dan wawancara. Observasi dilakukan diantaranya menijau berdasarkan suber Peta dasar kawasan TN Wasur, Peta zonasi TN Wasur, sedangkan wawancara dilakukan dengan masyarakat yang mendiami zona kawasan enclave yang ada di Sota.

Analisis data dilaksanakan melalui beberapa tahapan diantaranya: fokus diskusi dengan pengelola TN Wasur, konsultasi dengan Balai TN Wasur, verifikasi dilakukan terhadap interpretasi terhadap batas yang ditetapkan dan kebenaran kegiatan interpretasi penggunaan lahan. Verifikasi lapangan juga dilakukan terhadap zona penempatan, jumlah zona serta kebenaran isi zona yang telah ditetapkan.

Konsultasi publik dilaksanakan dengan melibatkan Pemerintah Daerah Kabupaten Merauke.

\section{HASIL DAN PEMBAHASAN}

\section{Keadaan Umum Taman Nasional Wasur}

Sebagaimana wilayah pengelolaan taman nasional lainnya, Taman Nasional Wasur dikelola berdasarkan zonasi, yang ditetapkan berdasarkan Keputusan Direktur Jenderal PHKA No. 15/KPTS/DJ-V/2001 terdiri atas: zona inti, zona rimba, zona pemanfaatan, dan zona pemukiman. Pengelolaan TN Wasur dapat dikembangkan dengna memperhatikan komitmen-komitemen dari segenap stakeholders dan peraturan yang berlaku agar dalam implementasinya tidak menimbulkan konflik di lapangan. Hasil ini tertuang dalam revisi zona TN Wasur yang mengacu pada Permenhut Nomor: P.56/Menhut-II/2006, tentang Pedoman Zona Taman Nasional yang telah melalui proses konsultasi publik di tingkat Kabupaten Merauke, yang dalam pelaksanaannya melibatkan para pihak yang berkepentingan diantaranya masyarakat adat yang terdiri dari 4 (empat) suku, Lembaga Swadaya Masyarakat (LSM), serta unsur pemerintah daerah mulai dari tingkat kampung, distrik (kecamatan), dan Satuan Kerja Perangkat Daerah (SKPD) terkait di Kabupaten Merauke.

Berdasarkan hasil kajian yang telah dilakukan bersama stakeholder, maka terdapat fungsi zona yang dapat digabungkan, yaitu fungsi zona rehabilitasi dan zona tradisional. Rumusan zona TN Wasur dapat dilihat pada Tabel 1 berikut. 
Tabel 1. Rumusan Zona TN Wasur, Fungsi dan Luasan

\begin{tabular}{lll}
\hline Nama Zona & Fungsi & Luas Area \\
\hline Zona Inti & $\begin{array}{l}\text { Perlindungan ekosistem, Potensi, sumber } \\
\text { plasma, dan budaya }\end{array}$ & \\
\hline Zona Rimba & $\begin{array}{l}\text { Sumber daya alam, lingkungan alam, 201.338 ha (48,65\%) } \\
\text { penelitian, penelitian, dan budidaya }\end{array}$ \\
\hline Zona Pemanfaatan & $\begin{array}{l}\text { Pariwisata alam, rekreasi, jasa 129 ha (0,03\%) } \\
\text { lingkungan, penelitian, pendidikan, dan } \\
\text { budidaya }\end{array}$ \\
\hline Zona Religi, Budaya, dan & $\begin{array}{l}\text { Situs budaya/ sejarah, pranata adat Marind 2.215 ha (0,54\%) } \\
\text { Sejarah }\end{array}$ \\
& $\begin{array}{l}\text { Ngawil anim, Kanume, Yelnan, dan } \\
\text { Marori Men-Gey }\end{array}$ \\
\hline Zona Khusus & $\begin{array}{l}\text { Area pemerintah kabupaten, masyarakat 34.644 ha }(8,37 \%) \\
\text { dan pihak pengembang ekonomi, }\end{array}$ \\
& pertahanan keamanan, sosial, dan budaya. \\
\hline
\end{tabular}

Berdasarkan Tabel 1 rumusan zona TN Wasur dapat dilihat bahwa luas zona rimba menjadi terluas di kawasan TN Wasur, dimana tujuan peruntukan lahan masih didominasi oleh sumber daya alam dan lingkungan alam, sedangkan luas kawasan pengembangan khusus pemerintahan, pemukiman masyarakat masih sangat luas, wilayah ini lah yang berkembang menjadi kawasan enclave untuk wilayah perbatasan Sota (RI-PNG).

Total luasan pengelolaan Balai Taman Nasional Wasur Kabupaten Merauke seluas 413.810 ha. Berikut merupakan Gambar 1 Peta kawasan Taman Nasional Wasur.

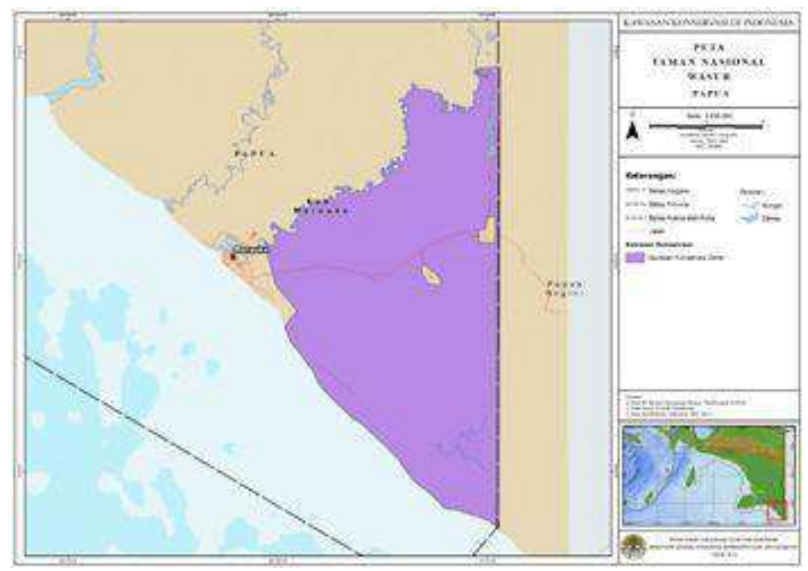

Gambar 1. Peta kawasan Taman Nasional Wasur (Sumber: Balai TN Wasur)

Berdasarkan Gambar 1 dapat dilihat bahwa sebagiaan besar kawasan pengelolaan Taman Nasional Wasur berada di kawasan Papua Selatan sampai perbatasan negara RI dan PNG.

\section{Keadaan Umum Distrik Sota}

Distrik Sota merupakan salah satu ditrik/ kecamatan yang ada di Kabupaten Merauke. Di sebelah timur Distrik Sota berbatasan langsung dengan Negara Papua New Guinea, di sebelah utara 
berbatasan dengan Distrik Elikobel, di sebelah barat berbatasan dengan Distrik Jagebob dan Distrik Tanah Miring, di sebelah selatan berbatasan dengan Distrik Merauke, dengan ketinggian 5-20 meter di atas permukaan laut. Berdasarkan data wilayah administrasi Distrik Sota terdiri dari Kampung Sota sendiri, Kampung Yanggandur, Kampung Torai dan Kampung Erambu. Luas Distrik Sota sekitar $2.843,21 \mathrm{~km}^{2}$ atau sekitar 6,07\% wilayah administrasi Kabupaten Merauke. Wilayah administrasi Distrik Sota berbatasan langsung dengan negara tetangga Papua New Guinea. Wilayah administrasi kampung pada Distrik Sota terdiri dari 5 kampung diantaranya: Kampung Sota, Yanggandur, Rawa Biru, Torai, dan Erambu. Gambar 2 merupakan gambar peta wilayah administrasi Distrik Sota (Agustan Latif, Agustan, 2017).

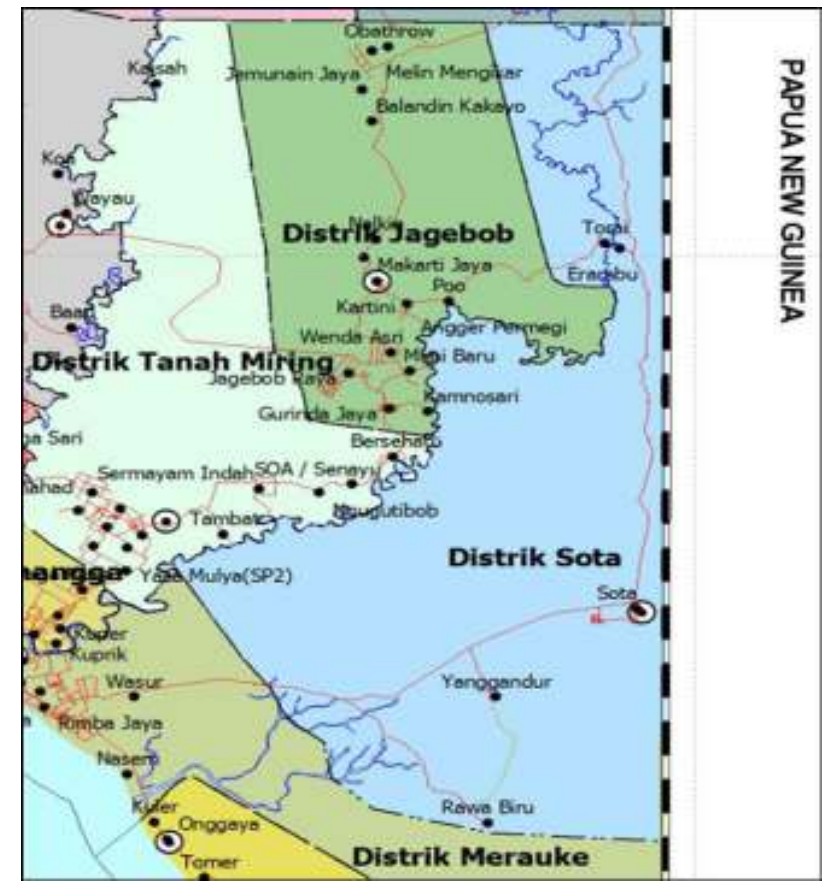

Gambar 2. Peta Wilayah Administrasi Distrik Sota (Agustan dan Widi, 2016 di dalam Agustan Latif dan Agustan, 2017)

Berdasarkan Gambar 2 dapat dilihat bahwa sebagian besar wilayah Taman Nasional Wasur berada di wilayah Distrik Sota Kabaupaten Merauke dan berbatasan langsung dengan negara tetangga Papua Nugini.

\section{Batasan dan Hakikat Zonasi Taman Nasional Wasur}

Agus Mulyana dkk. (2010) Pada dasarnya pengelolaan Taman Nasional di seluruh Indonesia sebagai kawasan yang ditetapkan untuk melindungi ekosistem asli dan dikelola oleh Balai Taman Nasional (BTN), dengan sistem zona dalam pemanfaatan untuk tujuan penelitian, ilmu pengetahuan, pendidikan, peningkatan budidaya, pariwisata, dan rekreasi (Undang-Undang No. 5 Tahun 1990). Berdasarkan pengelolaan menggunakan sistem zonasi ini memungkinkan pengelolaan secara bersama dengan mengakomodasi kepentingan masyarakat lokal wilayah perbatas Sota.

Mengacu pada perundangan bahwa perencanaan kawasan hutan harus memperhatikan kesejahteraan kawasan dalam penataan dan pengelolaan kawasan hutan. Dengan demikian 
keberadaan masyarakat adat yang sejak lama mendiami wilayah tersebut dan sudah memiliki sistem pengelolaan sumber daya alam di kawasan TN Wasur, harus diprioritaskan dalam sistem pengelolaan kawasan dan diakomodir kepentingannya dalam sistem pengelolaan taman nasional. Taman Nasional Wasur memiliki karakteristik pengelolaanyang berbeda dengan taman nasional lainnya karena berada pada wilayah masyarakat adat setempat, sehingga dalam proses penyusunan zona tidak dapat sertamerta dilakukan berdasarkan tahapan-tahapan formal yang telah ditetapkan pemerintah ataupun melalui sains moderen, melainkan diperlukan proses kompromi berdasarkan kepentingan masyarakat adat dan aturan-aturan tradisional pengelolaan sumber daya alamnya (Balai Taman Nasional Wasur, 2011).

Pada prinsipnya keberadaan masyarakat diantaranya ijin memanfaatkan dan hak mengelola kawasan secara ramah dan ramah lingkungan namun tidak mempunyai hak memiliki, melalui peraturan yang terikat berdasarkan kriteria diantaranya lingkungan (kesehatan ekosistem), ekonomi (tingkat penghidupan yang layak), sosial (kesetaraan antar kelompok), budaya (keutuhan dan identitas), serta politik (proses pengembilan keputusan yang adil dan transparan) (Agus Mulyana dkk., 2010).

\section{Kawasan Enclave Distrik Sota (Perbatasan RI - PNG)}

Agustan Latif dan Agustan (2017) dalam kajian berkaitan dengan karakteristik geospasial wilayah perbatasan RI-PNG di Distrik Sota, menuliskan bahwa wilayah perbatasan sota merupakan wilayah atau zona pengembangan (enclave) dengan indikasi tujuan wisata perbatasan berdasarkan rekomendasi kawasan oleh Balai Taman Nasional Wasur. Tingginya interaksi sosial anatara kedua negara (RI-PNG) berdampak positif terhadap pertumbuhan ekonomi, sosial dan budaya yang ada disekitar wilayah perbatasan sota. Pertumbuhan wilayah perbatasan sota berawal ketika Pemerintah Daerah Kabupaten Merauke menempatkan sebanyak 500 kepala keluarga untuk berdomisili di sota pada tahun 1993, yang mayoritas penduduknya meruapakan transmigrasi lokal masyarakat asli Papua.

Wilayah enclave berawal dari penempatan Kementerian Kehutanan, Dirjen Perlindungan Hutan dan Konservasi Alam Balai Taman Nasional Wasur mengeluarkan sebagian wilayah yang kemudian disebut zona enclave seluar 3000 ha dari kawasan konservasi hutan untuk warga transmigrasi lokal sebanyak 500 KK. Hasil realisasi penemparan ini berhasil dilakukan pada tahun 1994, kemudian berkembang hingga saat ini, tidak hanya transmigrasi lokal yang mendiami wilayah perbatasan sota saat ini, namun bertambah menjadi wilayah transmigrasi yang bersal dari pulau Jawa, sehinnga wilayah enclave ini dapat dikatakan berhasil dari segi pemanfaatan lahan. Berdasarkan data tersebut jika dibandingkan dengan keberadaan Distrik Sota Kabupaten Merauke secara umum telah memenuhi kriteria pemanfaatan lahan yakni luas wilayah Distrik Sota seluas 2.843,21 km², sedangkan zona pemanfaatan yang diberikan Balai Taman Nasional Wasur seluas 3000 ha.

Berikut ini Gambar 3 yang merupakan wilayah enclave dari TN Wasur. 


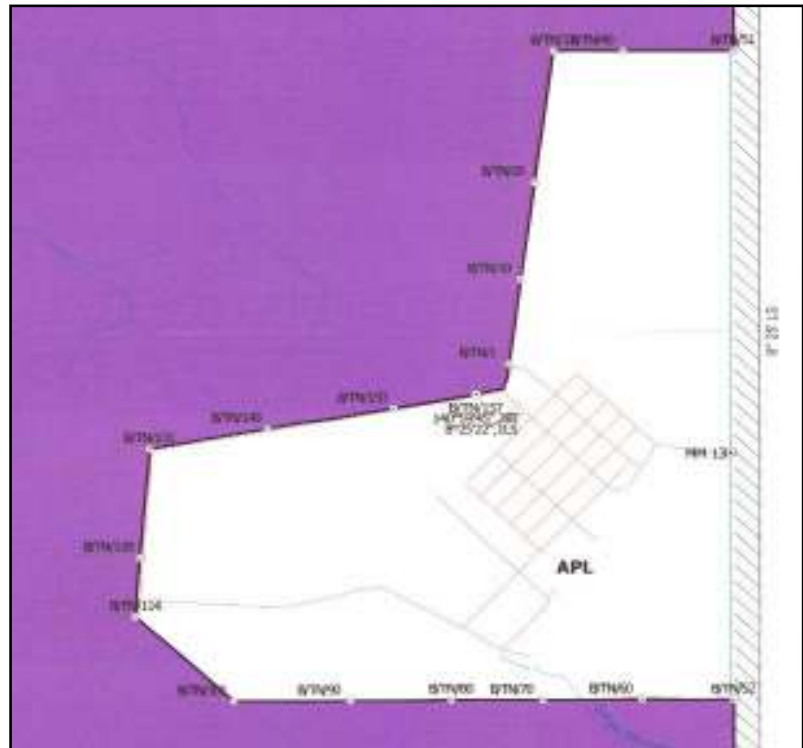

Gambar 3. Peta Zona Enclave Taman Nasional Wasur (Sumber: Taman Nasional Wasur, 2014 di dalam Agustan Latif dan Agustan, 2017)

Berdasarkan Gambar 3 dapat dilihat bahwa kawasan Wasur yang berwarna putih pada gambar dikelilingi oleh wilayah yang didominasi warna ungu yang merupakan wilayah kawasan Balai Taman Nasional Wasur. Hal ini menunjukkna bahwa wilayah sota merupakan wilayah pemanfaatan, pengembangan penduduk, dan pusat pengembangan wilayah TN Wasur yang mengarah pada pengembangan pariwisata perbatasan negara.

\section{Wilayah Enclave Balai Taman Nasional Wasur di Perbatasan Sota}

Sejak ditetapkan sebagai wilayah transmigrasi lokal pada tahun 1993 oleh Pemerintah Kabupaten Merauke kepada Kampung Sota, yang sebelumnya merupakan wilayah Balai Taman Nasional Wasur, Kampung Sota mulai tumbuh interaksi masyaratak baik secara sosial, ekonomi dan budaya antara suku-suku papua yang berdomisili di wilayah perbatasan Sota RI-PNG menyebabkan munculnya jalur-jalur setapak sebagai akses jalan darat diri Sota ke negara tetangga yakni Kampung Weam di Papua Nugini. Seiring dengan mobilisasi antara kedua warga negara tersebut melalui jalur darat secara tradisional yang dibatasi oleh garis batas kedua negara.

Pertumbuhan kawasan enclave di Sota secara positif memberikan manfaat bagi warga masyarakat Sota, baik secara ekonomi, pendidikan, sosial dan budaya. Salah satu yang dominan muncul pusat-pusat perdagangan baik di pasar perbatasan maupun yang berada diwilayah tugu perbatasan RI-PNG.

\section{KESIMPULAN}

Berdasarkan hasil kajian pemanfaatan wilayah enclave Taman Nasional Wasur, menghasilkan beberapa kesimpulan diantaranya:

a. Hasil pemanfaatan lahan enclave telah sesuai dengan rekomendasi baik oleh Pemerintah Daerah Kabupaten Merauke dan Balai Taman Nasional Wasur sebagai otoritas pengelola kawasan konservasi Taman Nasional Wasur. 
b. Berdasarkan hasil investigasi studi literatur dan kajian lapangan, rekomendasi serta analisis kawasan enclave telah berhasil. Hal ini diwujudkan dengan adanya pertumbuhan secara signifikan kawasan Sota baik secara ekonomi, pendidikan, sosial dan budaya.

c. Program transmigrasi yang ditempatkan di kawasan perbatasan negara khususnya di Sota dari pulau Jawa dapat memberikan kontribusi positif kepada masyarakat lokal Papua.

Berdasarkan kajian di atas dalam mewujudkan pemanfaatan enclave wilayah perbatasan yang lebih baik dan sebagai upaya perlu dilakukan beberapa hal yang penting diantaranya:

a. Perlu adanya pemahaman pemanfaatan kawasan yang lebih baik dari segi ekonomis dan produktifitas pengelolaan lahan demi peningkatan kesejahteraan masyarakat lokal Papua yang berdomisili di perbatasan negara.

b. Diperlukan peningkatan infrastruktur yang memadai sebagai upaya memudahkan akses perdagangan antara kedua negara.

c. Perlu adanya kajian sehubungan dengan pemanfaatan lahan produktif di wilayah Taman Nasional Wasur.

\section{REFERENSI}

[1] Balai Taman Nasional Wasur. 2011. Review Zonasi Taman Nasional Wasur. Balai TN Wasur, Merauke, Papua

[2] Mulyana, A. Moeliono, M. Munnigh, P . Indriatmoko, Y. Limberg, G. Utomo, N. A. Iwan, R. Saparuddin dan Hamzah. (2010). Kebijakan pengelolaan zona khusus, dapatkah meretas kebuntuan dalam menata ruang taman nasional di Indonesia. Brief No 1, April 2010, Center For International Forestry Research. http://www.cifor.cgiar.org

[3] Latif, A dan Agustan. 2017. Karakteristik Data Geospasial Sebagai Dasar Perencanaan untuk Memperkuat Ketahanan Perbatasan NKRI (Studi kasus: Perencanaan Kota Perbatasan Distrik Sota dengan Papua Nugini di Merauke Provinsi Papua). Jurnal Ketahanan Nasional, Vol. 23, No. 3. Yogyakarta

[4] Sawitri, R dan Adelina, Y. 2016. Kajian Usulan Zona Khusus Taman Nasional Kutai (Studi on Special Use Zone Proposal ini Kutai National Park). Jurnal Penelitian Hutan dan Konservasi Alam. Vol. 13 No. 2 Hal. 85-100.

[5] Taena, W. 2009. Kajian Pengembangan Ekonomi Wilayah Perbatasan Kabupaten Timor Tengah Utara dengan District Enclave Oekusi. Tesis. Sekolah Pascasarjana. Institut Pertanian Bogor. Bogor.

[6] Taena, W. Rustiadi, E. dan Hariyoga, H. 2010. Pengembangan Wilayah Perbatasan Kabupaten Timor Tengah Utara dengan Distrik Enclave Oukusi Sebagai Kawasan Agropolitan. Forum Pascasarjana, Vol. 33 No. 1 Hal 35-53. Bogor. 